\title{
Why Do Migratory Birds Sing on Their Tropical Wintering Grounds?
}

\author{
Marjorie C. Sorensen, ${ }^{1, \star}$ Susanne Jenni-Eiermann, ${ }^{2}$ and Claire N. Spottiswoode ${ }^{1,3}$ \\ 1. Department of Zoology, University of Cambridge, Cambridge CB2 3EJ, United Kingdom; 2. Swiss Ornithological Institute, \\ Sempach CH-6204, Switzerland; 3. Department of Science and Technology-National Research Foundation Centre of Excellence, \\ Percy FitzPatrick Institute, University of Cape Town, Rondebosch 7701, South Africa
}

Submitted June 4, 2015; Accepted August 7, 2015; Electronically published January 26, 2016

Online enhancements: appendix. Dryad data: http://dx.doi.org/10.5061/dryad.38f3n.

\begin{abstract}
AвSTRACT: Many long-distance migratory birds sing extensively on their tropical African wintering grounds, but the function of this costly behavior remains unknown. In this study, we carry out a first empirical test of three competing hypotheses, combining a field study of great reed warblers (Acrocephalus arundinaceus) wintering in Africa with a comparative analysis across Palearctic-African migratory songbird species. We asked whether winter song (i) functions to defend nonbreeding territories, (ii) functions as practice to improve complex songs for subsequent breeding, or (iii) is a nonadaptive consequence of elevated testosterone carryover. We found support for neither the longassumed territory-defense hypothesis (great reed warblers had widely overlapping home ranges and showed no conspecific aggression) nor the testosterone-carryover hypothesis (winter singing in great reed warblers was unrelated to plasma testosterone concentration). Instead, we found strongest support for the song-improvement hypothesis, since great reed warblers sang a mate attraction song type rather than a territorial song type in Africa, and species that sing most intensely in Africa were those in which sexual selection acts most strongly on song characteristics; they had more complex songs and were more likely to be sexually monochromatic. This study underlines how sexual selection can have far-reaching effects on animal ecology throughout the annual cycle.
\end{abstract}

Keywords: great reed warbler, Palearctic-African migrants, winter, nonbreeding, song function.

\section{Introduction}

Animal communication in the context of breeding has been intensively studied; the selective forces shaping vivid displays such as elaborate and brightly colored plumage, deer rut calls, and complex bird vocalizations are predominantly well understood (Andersson 1994). However, we know very little about the function of sexual signals pro-

\footnotetext{
* Corresponding author; e-mail: marjoriesorensen@gmail.com.
}

Am. Nat. 2016. Vol. 187, pp. E65-E76. (C) 2016 by The University of Chicago. 0003-0147/2016/18703-56314\$15.00. All rights reserved. DOI: $10.1086 / 684681$ duced at other times of the year. Birdsong has been a particularly well-studied sexual signal, and singing is known to be important for pairing date, number of females attracted, number of offspring sired, and offspring viability (Catchpole and Slater 2003). Yet, many long-distance migratory songbirds sing during the nonbreeding season, too; for example, $62 \%$ of Palearctic-African migrants sing in sub-Saharan Africa during the northern winter, thousands of kilometers away from their breeding grounds (Cramp and Perrins 1994). Remarkably, we still do not know the function of this behavior. Given that song production increases predation risk, consumes time that could otherwise be spent foraging, and is generally considered energetically expensive (Gil and Gahr 2002; Hasselquist and Bensch 2008), we should expect an adaptive explanation for such winter singing.

In this study, we test three hypotheses for the existence of winter song by way of comparative analyses across PalearcticAfrican migratory songbird species in combination with a field study of the great reed warbler (Acrocephalus arundinaceus), a 30-g Palearctic-African trans-Saharan migrant, on its wintering grounds in Zambia. Great reed warblers sing persistently in tropical Africa (Hedenström et al. 1993), and anecdotal sightings of solitary birds have been interpreted to suggest that individuals are territorial and occupy winter feeding territories (Verheyen 1953; Brosset 1971). Males sing two song types during breeding: one long song type that consists of a wide variety of syllables and functions in mate attraction and a second, shorter song type that consists of relatively few syllables and is used for breeding-territory defense (Catchpole 1983). Field experiments during breeding have demonstrated that their song is particularly expensive, requiring more than $50 \%$ more energy than basal energetic rates (Hasselquist and Bensch 2008), and exhaustive research has shown positive effects of male song quality on multiple parameters of reproductive success (Catchpole 1986; Catchpole et al. 1986; Hasselquist et al. 1996). Here, we first describe the unstudied natural history of winter singing behav- 
ior in great reed warblers and test whether winter songs differ from those sung during breeding. Then we use a combination of radio telemetry, playback experiments, testosterone assays, and comparative analyses across PalearcticAfrican migratory songbird species to test three competing hypotheses (predictions summarized in table 1) to explain investment in winter song by Palearctic-African migratory songbirds.

First, we tested the long-standing hypothesis that winter song functions for the defense of individual feeding territories. This territory-defense hypothesis appears to be the generally accepted default explanation for the function of winter song, and consequently, singing in Africa has often been used as an indicator of winter territoriality (Cramp and Perrins 1994). However, this hypothesis has rarely been empirically tested. In two studies of winter song, marsh warblers (Acrocephalus palustris) were found to start singing only after aggressive behavior was complete (Kelsey 1988), and willow warbler (Phylloscopus trochilus) behavior did not correspond with predictions for individual territory defense but, puzzlingly, with group defense of short-term territories (Sorensen 2014). In our study, if great reed warblers use song to defend winter feeding territories, then we should expect both sexes to sing (as they do on the breeding grounds; Cramp and Perrins 1994), we should expect winter song type to correspond to the short territorial-defense song (Catchpole 1983), and we should expect individuals to be site-faithful with little overlap in space use and to be aggressive toward conspecifics. Additionally, we should expect birds singing most intensely during the winter to be the highest-quality individuals (a prediction shared by all three hypotheses), due to the high energetic costs associated with song production in this species.

Second, we tested an alternative adaptive explanation for winter singing: that it functions to improve song quality. This hypothesis is based on the premise that for many migratory bird species, including great reed warblers, song quality is known to improve with age (Forstmeier et al. 2006; Kipper and Kiefer 2010). Because song quality confers reproductive benefits (Catchpole and Slater 2003), selection may favor in- dividuals that are able to improve their songs via practice during the nonbreeding season. Long-distance migrants can modify their songs on the wintering grounds; for example, marsh warblers incorporate mimicry of African species into their repertoires given in Europe the following summer (Dowsett-Lemaire 1979).

We predicted that if winter singing functions to improve breeding-song quality in great reed warblers, then only males should sing, since only males stand to gain sexually selected benefits of practice; moreover, they should sing the long mate-attraction song type. In addition to these predictions testable in our field study on the singing behavior of great reed warblers in Zambia, the song-improvement hypothesis also makes clear comparative predictions across PalearcticAfrican migratory songbird species. For many of these species, the metabolic costs of song are likely to be lower than the high costs observed for our focal species, the great reed warbler (Oberweger and Goller 2001; Ward et al. 2003); however, opportunity costs (e.g., predator avoidance, taking time away from foraging) are likely to remain high for other species in a range of ecological settings (Gil and Gahr 2002). Such costs should make any causal association between investment in song production in Africa and more intense sexual selection for song quality on the breeding grounds more broadly applicable across species. Therefore, we test the prediction that winter singing should be more likely in Palearctic-African migratory songbird species with (i) higher song complexity and (ii) lower sexual dichromatism, since theory predicts that the availability of visual cues for male quality should reduce the strength of sexual selection on song (Roff 1992).

Finally, we tested a potential nonadaptive explanation for winter singing. During the breeding season, singing activity is specifically related to gonadal androgens (Fusani 2008); however, testosterone levels drop to basal levels in many bird species during the winter (Logan and Wingfield 1990; Schwabl 1992). Indeed, winter singing may be stimulated by several different hormonal mechanisms (possibly due to the high costs of maintaining elevated testosterone; Soma 2006), any

Table 1: Comparative analysis of predictors of singing intensity in Africa across 57 species of Palearctic-African migratory bird

\begin{tabular}{llccc}
\hline Variable & $\lambda$ & pm & CI & pMCMC \\
\hline Song repertoire size & .73 & 9.99 & 1.30 to 22.42 & .002 \\
Syllable repertoire size & .45 & 2.45 & -.12 to 5.27 & .04 \\
Versatility index & .63 & 27.59 & -1.17 to 69.53 & .03 \\
Sexual dichromatism & .85 & -12.81 to -10.93 & -27.60 to $-21.43 ;-2.95$ to -2.39 & $.0001-.0007$ \\
\hline
\end{tabular}

Note: These models (MCMCglmm; see the main text for details) show that the intensity of winter song (assigned to three categories: rare, infrequent, and frequent) is predicted by song complexity and sexual dichromatism (two measures of the strength of sexual selection on male song), supporting the song-improvement hypothesis. Sexual dichromatism was included as a covariate in each of three models (song repertoire size, syllable repertoire size, and versatility index), and therefore we present the range of parameter values. After Bonferroni correction, syllable repertoire size and versatility index become nonsignificant at $P=.05$. CI $=$ confidence interval; $\mathrm{pm}=$ posterior mean. 
of which might mechanistically underpin the adaptive hypotheses above. The potential for nonadaptive singing arises because high testosterone levels during breeding may, at least in some individuals, carry over to the winter period or rise in anticipation of spring migration (since testosterone helps to mediate premigratory fat deposition; Deviche 1995). This may potentially stimulate singing via gonadal androgens without an associated fitness benefit (Sorensen 2014). If such testosterone carryover stimulates winter song, then we expect that only males should sing, that males who sing should have higher levels of circulating testosterone than those who do not sing, and that singing should increase in frequency as spring migration approaches.

\section{Methods \\ Study Site and Species}

We conducted fieldwork in southern Zambia, $20 \mathrm{~km}$ north of Choma, in 280 ha of mesic grassland and reed-bed habitat around two dams (dam 1: $16^{\circ} 39^{\prime} 03^{\prime \prime} \mathrm{S}, 27^{\circ} 00^{\prime} 00^{\prime \prime} \mathrm{E}$; dam 2: $16^{\circ} 37^{\prime} 18^{\prime \prime} \mathrm{S}, 26^{\circ} 59^{\prime} 35^{\prime \prime} \mathrm{E}$ ) and their associated watercourses from January to April of 2011 and 2012. The surrounding habitat is thornbush savannah, broad-leaved woodland, and tobacco and maize cultivation. Great reed warblers breed in Europe and arrive in Zambia after replacing their flight feathers at staging sites farther north within sub-Saharan Africa (Hedenström et al. 1993). The average first arrival date for great reed warblers in Zambia is November 20, with most birds arriving by mid-January; the average last departure date is April 4 (Dowsett et al. 2008).

\section{Capture and Radio Telemetry}

Great reed warblers were captured using 8-10 mist nets erected daily from 0530 to 1100 hours. Birds were captured without the use of playbacks to avoid biases toward the most aggressive individuals or sex. At the time of capture, all individuals were ringed with a unique combination of three colored leg rings and a numbered aluminum ring, were weighed with an electronic scale $( \pm 0.01 \mathrm{~g})$, and had their tarsus length, bill length, and wing length measured with digital calipers $( \pm 0.01 \mathrm{~mm})$. To estimate body condition, we calculated the scaled mass index from our morphometric data. This scales the mass of all individuals to what would be expected if they were all of identical body size and is preferable to the more traditionally used residuals of mass on length (Peig and Green 2009). We used wing length as our measure of structural size because it was correlated most strongly with mass $(r=0.46, P<.001, n=61)$ and because a single measure of size is preferable to a principal component analysis (PCA) of multiple measures, as PCA complicates the interpretation of scaling relationships (Peig and Green 2009). Because great reed warblers are sexually monomorphic, a 50- $\mu \mathrm{L}$ blood sample was taken to determine sex using a molecular technique. Primers for molecular sexing were modified from the primers $2550 \mathrm{~F}$ and $2718 \mathrm{R}$ first described by Fridolfsson and Ellegren (1999); see Round et al. (2007) for details. From January 28 to March 3 of 2012, 25 great reed warblers were captured and fitted with radio transmitters (Holohil BD-2, Carp, Ontario, Canada; $1.25 \mathrm{~g}, 4.3 \%$ body weight, 9-week transmitter life) using a leg harness (Rappole and Tipton 1991). Radio receivers and two element-H antennas were used to acquire daily locations for each tagged individual (Telonics, Mesa, AZ). Home ranges were calculated using 95\% fixed kernel estimates of the utilization distribution, which is a robust technique for realistically estimating where animals are most likely to be located over time (Seaman and Powell 1996). To determine the degree of home-range overlap, we used the HR method of the adehabitatHR package, which computes the proportion of the home range of one animal covered by the home range of another (Calenge 2006). We report both the total area covered and the average number of individuals overlapping within each home range. Overlap analyses were repeated with females excluded. The date of arrival to breeding grounds has significant consequences for reproductive success, as the earliest-arriving males have improved pairing success, fledgling success, and number of offspring recruits to the breeding population the following summer (Hasselquist 1998); therefore, departure date of spring migration was used as an additional metric of individual quality. Departure date was taken as the last date each radio-marked bird was detected. Radio signals were checked for two subsequent days after departure to ensure that signals had not simply been undetected.

\section{Winter and Summer Song Comparison}

We compared 20 great reed warbler songs recorded during the breeding season throughout central Europe (downloaded from the Xeno-Canto database: http://www.xeno-canto.org) to 18 songs recorded from different individuals in Zambia. In Zambia, song recordings were made between 0530 and 1100 hours from January to April of 2011 and 2012 using a Sennheiser ME 66 directional microphone within $15 \mathrm{~m}$ (or less) of the focal individual. Singing birds were identified visually by their unique combination of colored leg rings, thus ensuring that recordings came from different individuals. To determine singing activity during the winter (fig. 1), the number of singing great reed warblers encountered from 0530 to 1100 hours at a subset of the study area (dam 1) was recorded at the end of each morning in the field (these observations were not always confirmed with visual identification; therefore, we cannot exclude the possibility that some individuals may have been recorded more than once). Great reed warblers are known to have weak migratory connectivity, 


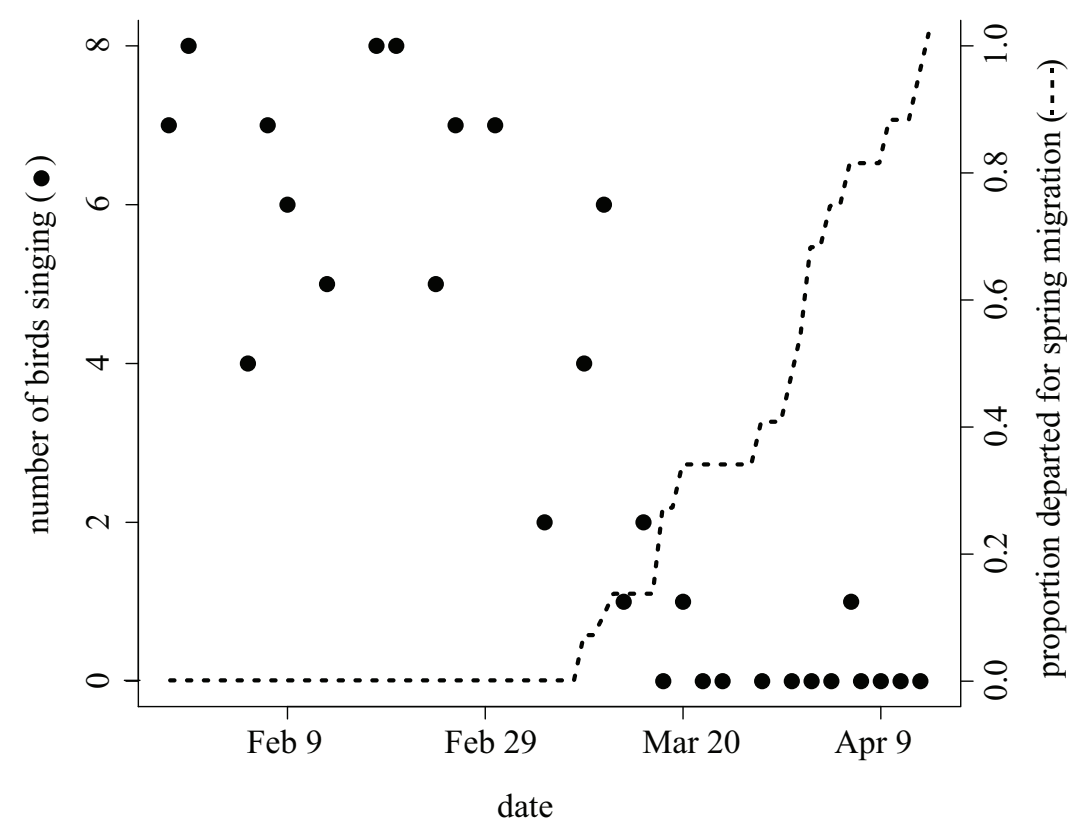

Figure 1: Relationship between the number of great reed warblers heard singing and the proportion of radio-tracked birds remaining on site at dam 1 (i.e., not yet departed for spring migration) in 2012 (the latter data were unavailable for 2011). Singing decreased in frequency as migration approached, contrary to expectations for the testosterone hypothesis.

such that individuals from a single breeding or wintering location disperse widely (over thousands of kilometers) during the subsequent season (Lemke et al. 2013). Nonetheless, to minimize any possible effects of geographic variation on song features, we analyzed breeding songs from throughout central Europe. Mitochondrial DNA analyses of individuals from our study population suggest that this is their most likely breeding area (N. El Arabany and B. Hansson, unpublished data). We produced spectrograms using Sonic Visualiser (Cannam et al. 2010) and measured syllable repertoire size, syllable repeats, song rates (songs/minute), and song duration for all breeding and winter songs. The number of syllables (different sounds) is commonly quantified for great reed warblers and other Acrocephalus species, and we followed established methods in doing so (Catchpole 1986; Hasselquist 1998). Total repertoire size was calculated from 10 continuous songs, after which syllable repertoire size levels off (Hasselquist et al. 1996). Syllable repeats were measured as the number of times each syllable is repeated within a song.

\section{Playback Experiments}

We estimated conspecific aggression of radio-tagged birds by measuring their response to song playback combined with a taxidermic model presentation. Presentations were made between 0600 and 0830 hours, when birds were most active. We used radiotelemetry to locate birds to within $10 \mathrm{~m}$ and then placed a speaker (RadioShack miniamplifier) on the ground below a great reed warbler taxidermic model suspended $\sim 1.5 \mathrm{~m}$ above the ground (Marra 2000). One of four different songs was used in each trial, all recorded from different individuals at the same site during the previous year. All four songs had similar song lengths (8.2 s; range: 6.8$10.2 \mathrm{~s}$ ) and intersong intervals (3.2 s; range: $2.1-5.1 \mathrm{~s})$. The observer operated the playback from a concealed position $15 \mathrm{~m}$ away. Following Sorensen (2014), after $10 \mathrm{~min}$ the response was classified as follows: $0=$ no response; $1=$ birds moved toward the presentation but not closer than $10 \mathrm{~m}$, and no "chipping" alarm calls were heard; $2=$ chipping and approach to $<10 \mathrm{~m} ; 3=$ chipping and approach to $<5 \mathrm{~m} ; 4=$ chipping and approach to $<3 \mathrm{~m} ; 5=$ attacked the model.

\section{Testosterone Assays}

To quantify winter levels of circulating testosterone, we took a $50-\mu \mathrm{L}$ blood sample within $8 \mathrm{~min}$ of capture. Blood samples of birds were collected into heparinized microhematocrit capillary tubes from the brachial vein. Samples were immediately stored on ice and centrifuged (max speed of 8,000 rpm) for $10 \mathrm{~min}$ within $4 \mathrm{~h}$ of collection. Plasma was stored in 0.5-mL Eppendorf tubes at $-20^{\circ} \mathrm{C}$. Plasma was transported on ice to the Swiss Ornithological Institute (Sempach, Switzerland), where testosterone was analyzed with a commercial 
testosterone enzyme immunoassay kit (ADI-900-065, Enzo Life Sciences). The performance characteristics were tested by the manufacturer according to the guidelines listed in the National Committee for Clinical Laboratory Standards evaluation protocols. The sensitivity of the assay is $5.67 \mathrm{pg} /$ $\mathrm{mL}$. The cross-reactivity for testosterone is $100 \%$, for 19 hydroxytestosterone is $14.64 \%$, for androstenedione is $7.20 \%$, for estradiol is $0.40 \%$, and for dihydrotestosterone, estriol, aldosterone, corticosterone, cortisol, cortisone, estrone, progesterone, and pregnenolone is $<0.001 \%$. Before analysis, testosterone in plasma (diluted $1: 10$ in double-distilled $\mathrm{H}_{2} \mathrm{O}$ ) was extracted with $2 \mathrm{~mL}$ diethyl ether, shaken for $30 \mathrm{~min}$, and incubated for another $30 \mathrm{~min}$ at room temperature. Thereafter, the upper phase was decanted. This procedure was repeated once. The combined extracts were evaporated and resuspended with assay buffer (dilution 1:7.33). A dilution curve with a pool sample showed linearity with the standard curve. To provide the most conservative estimate for statistical comparisons, samples in which hormone levels could not be detected ( $n=6$ of 29) were set to the detection limits of the assay. All samples were analyzed together on one microtiter plate.

\section{Comparative Analysis}

We collated information on winter singing intensity in 57 Palearctic-African migratory passerine species wintering in sub-Saharan Africa, obtained from the literature (Cramp and Perrins 1994) and supplemented by accounts from researchers in the field (F. Dowsett-Lemaire and T. Fulford; data available in the Dryad Digital Repository: http://dx.doi .org/10.5061/dryad.38f3n [Sorensen et al. 2015]). Comparative tests across species accounted for phylogenetic relatedness using a cladogram compiled from published data (see fig. A1, available online, for data sources). Because information on Palearctic-African migrant ecology is scarce and qualitative, we scored winter singing intensity in three categories: rare, infrequent, and frequent. Species were categorized as rare if song was never recorded in Africa (we used "rare" to describe this category since we cannot exclude the possibility that the species does sing but has simply never been recorded doing so), infrequent if the species had been reported to sing in Africa but not on a regular or daily basis, and frequent if the species was reported to sing regularly in Africa, usually daily.

We measured song complexity from recordings on the Xeno-Canto database. For each species, 10 songs were analyzed for syllable repertoire size, song repertoire size, and versatility index. Song measurement protocols were the same as for "Winter and Summer Song Comparison" above, with the addition of (i) song repertoire size (the mean number of song types given by each of the 10 individuals) and (ii) versatility (how frequently song types were switched within a bout of singing). Following Read and Weary (1992), species were categorized as either immediately versatile, where song types were rapidly switched; eventually versatile, where song types were repeated several times before switching; or nonversatile, where a single song type was simply repeated throughout a song bout. In addition to song-complexity measures, we also included plumage-dichromatism scores in our analyses. Plumage dichromatism was assessed from color illustrations (Svensson et al. 2009) by an observer naïve to the hypothesis being tested. Following Owens and Bennett (1994), each of five body regions was given a score of 0 (no difference between sexes), 1 (difference in shade or intensity), or 2 (difference in color or pattern), and these were summed to yield an overall score on a scale of 0 (monomorphic) to 10 (max dichromatism). This method may underestimate sexual dichromatism perceptible to avian vision via, for example, ultraviolet signals (but see Seddon et al. 2010), but this should not introduce any bias with respect to the hypothesis being tested.

We used R, version 2.15.1 (R Development Core Team 2012), to implement phylogenetically controlled generalized linear models using Markov chain Monte Carlo methods (MCMCglmm) to evaluate our predictions while controlling for phylogeny (Hansen 1997). We chose an MCMCglmm approach because our response variable (winter singing intensity) was ordinal, which no other method can robustly assess. Branch lengths were estimated by Grafen's (1989) method in the ape package. We ran each analysis with two different priors: inverse Wishart and inverse gamma. The two different priors led to very similar estimates for the fixed terms, so we report the values from the inverse Wishart prior. Each analysis was repeated three times, and terms were considered statistically significant when the calculated PMCMC values were less than 0.05 . Because collinearity between song-complexity measures was high $\left(r_{\mathrm{s}}=0.63-0.90\right)$, we ran separate models for each complexity measure while including sexual dichromatism as a covariate.

\section{Nonphylogenetic Statistical Analyses}

We used unequal variance (Welch's) $t$-tests on ranked data to test for differences in the central tendency of two groups, following Ruxton (2006). All means are given \pm SE.

Results

\section{The Natural History of Winter Singing}

None of 21 individually marked female great reed warblers in Zambia sang, but $49 \%$ of 43 males sang. Singing intensity decreased (fewer males were heard singing daily between 0530 and 1100 hours) prior to and during the initiation of migratory departures (fig. 1). For example, on March 20, 
2012, singing had stopped (one more song was heard on April 5), yet 50\% of radio-tracked males known to have sung that season and $67 \%$ of all radio-tracked birds remained on site. In our Zambian study area, great reed warblers sang the long song type (Zambian songs were even longer than European songs and equally complex; see below), which is used for mate attraction on the breeding grounds, rather than the short stereotyped song that functions in territory defense (Catchpole 1983).

Although songs given in Zambia corresponded to the complex mate-attraction song type (fig. 2), they differed in several respects from typical breeding songs: song rate (songs/ minute) was significantly lower $\left(t_{34.2}=4.37, P<.001\right.$; Zambia: mean $\pm \mathrm{SE}=4.9 \pm 0.4$; Europe: mean $\pm \mathrm{SE}=7.2 \pm$ $0.5)$, syllables were repeated fewer times $\left(t_{33.7}=7.69, P<\right.$ .001; Zambia: mean \pm SE $=1.8 \pm 0.03$; Europe: mean \pm $\mathrm{SE}=2.51 \pm 0.1)$, and songs were longer $\left(t_{34.7}=-2.61\right.$, $P=.01$; Zambia: mean $\pm \mathrm{SE}=6.9 \pm 0.75 \mathrm{~s}$; Europe: mean $\pm \mathrm{SE}=4.6 \pm 0.23 \mathrm{~s}$ ). There was a tendency toward longer intersong intervals in Zambia, but this trend was not significant $\left(t_{35.8}=-1.59, P=.11\right.$; Zambia: mean $\pm \mathrm{SE}=$ $6.7 \pm 1.1 \mathrm{~s}$; Europe: mean $\pm \mathrm{SE}=4.2 \pm 0.3 \mathrm{~s}$ ). However, song repertoires did not differ in complexity, since the mean number of syllables produced was similar in each location $\left(t_{33.9}=0.39, P=.69\right.$; Zambia: mean $\pm \mathrm{SE}=22.6 \pm 0.8$; Europe: mean $\pm S E=23.1 \pm 0.9)$. In summary, great reed warblers wintering in Zambia sang songs that were less repetitive and longer than those sung during breeding, but the songs were equally complex.

All three hypotheses tested below shared the prediction that singing males should be the highest-quality individuals (fig. 3). Great reed warbler males that sang in Zambia were indeed in better condition (scaled mass index: $t_{36.5}=$
$-3.43, P=.001)$ and tended to leave earlier for spring migration (departure date: $t_{12.4}=2.05, P=.06$ ) than those that did not sing (fig. 4).

\section{Does Winter Song Function to Defend Winter Territories?}

We found support for two of seven predictions associated with the territory-defense hypothesis (fig. 3). Great reed warbler home ranges (95\% utilization distributions) overlapped extensively. Individual home ranges overlapped with those of an average of $11.4 \pm 0.49$ SE other individuals. Average spatial overlap between home ranges was $49.1 \% \pm 0.05 \%$. When females were excluded from the analysis, the extent of overlap remained high (fig. 5): each individual overlapped with $9.6 \pm 0.36$ other individuals, covering just over half of each individual's home range (average extent of spatial overlap: $51.0 \% \pm 0.05 \%)$. This suggests that wintering great reed warblers have widely overlapping home ranges rather than distinct territory boundaries.

Great reed warbler aggression in response to song playback in combination with a conspecific model presentation was very low. In 17 of 21 trials, no response was observed (Pearson's $\chi^{2}$ test: $\chi^{2}=11.56, P<.001$ ). In the four trials $(16 \%)$ that elicited a response, the targeted bird moved toward the playback (response category 1) but came no closer than $10 \mathrm{~m}$, suggesting no aggression in response to homerange intrusion and very low levels of conspecific aggression. Observations in the field also support these findings. Chases between individuals were never observed, and often two or more individuals were seen within close $(<5 \mathrm{~m})$ proximity to each other. On one occasion, two males were seen singing within $3 \mathrm{~m}$ of each other and demonstrating no interindividual aggression.

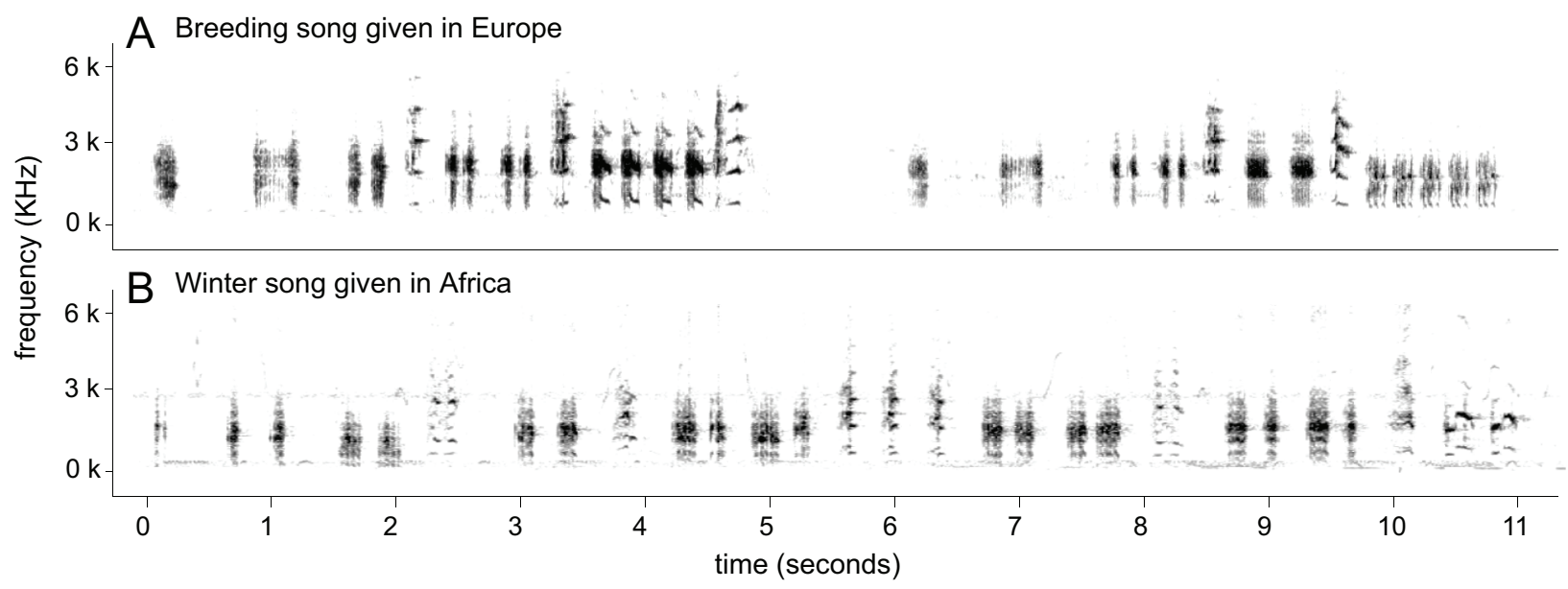

Figure 2: Spectrograms of examples of great reed warbler songs given during mate attraction on the breeding grounds in Europe during the northern summer $(A)$ and on the wintering grounds in Zambia $(B)$, illustrating how winter songs are longer and have more repeated syllables than breeding songs (see the main text for details). 


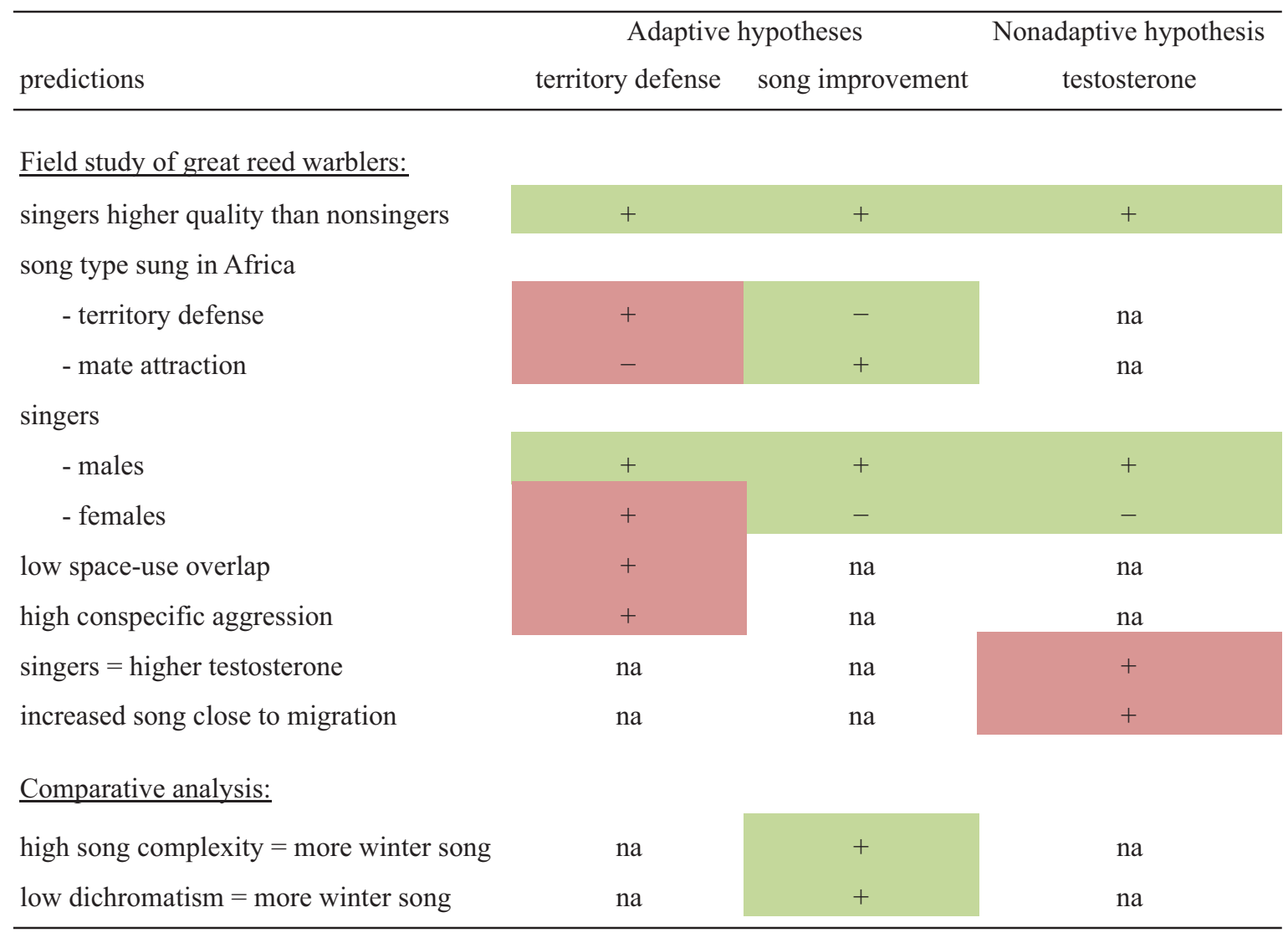

Figure 3: Three hypotheses and associated predictions to explain the function of winter song in long-distance migratory birds. Hypotheses tested are (i) the territory-defense hypothesis, (ii) the song-improvement hypothesis, and (iii) the testosterone hypothesis. Green cells indicate support for the designated prediction; red cells indicate lack of support. The comparative analysis utilizes information on winter singing intensity, dichromatism, and song-complexity measures from 57 Palearctic-African migratory songbird species (see "Comparative Analysis" in "Methods").

Does Winter Song Function to Improve Breeding Songs?

We found support for all seven predictions associated with the song improvement hypothesis (fig. 3). In our comparative analysis of Palearctic-African migrant songbird species, the maximum likelihood estimate of Pagel's $\lambda$ for winter singing intensity was 0.64 and differed significantly from both 0 and $1(P<.001)$, indicating a moderate influence of phylogeny on this trait. Table 1 shows that winter singing intensity was significantly related to song repertoire size, syllable repertoire size, and versatility index (under conservative Bonferroni correction, the latter two become nonsignificant at $P=.05$ ); in each case, species with more complex or versatile songs sang more in Africa. Additionally, in each model, winter singing intensity was also significantly predicted by sexual dichromatism, such that more dichromatic species sang less than monochromatic species when on their African wintering grounds (table 1). Sexual dichromatism was unrelated to syllable repertoire size (poste- rior mean $[\mathrm{pm}]=8.59$; confidence interval $[\mathrm{CI}]=-6.73$ to $28.24 ; \mathrm{pMCMC}=0.26)$ or song repertoire size $(\mathrm{pm}=$ -1.58 ; $\mathrm{CI}=-5.91$ to 2.58 ; $\mathrm{pMCMC}=0.41$ ). This implies (i) that there was no risk of collinearity in the analyses above and (ii) that despite their common association with the incidence of winter singing, more dichromatic species do not necessarily have simpler songs.

\section{Is Winter Song Associated with Elevated Winter Testosterone Levels?}

We found support for three of five predictions associated with the testosterone hypothesis (fig. 3). Great reed warbler males that sang in Zambia did not have higher plasma testosterone level concentrations than those that did not sing (fig. $6 ; t_{24.9}=-0.83, P=.42$; singers: mean $\pm \mathrm{SE}=$ $276.4 \pm 67.4 \mathrm{pg} / \mathrm{mL}$; nonsingers: mean $\pm \mathrm{SE}=263.0 \pm$ $70.1 \mathrm{pg} / \mathrm{mL}$ ). Singing did not increase in frequency as spring 

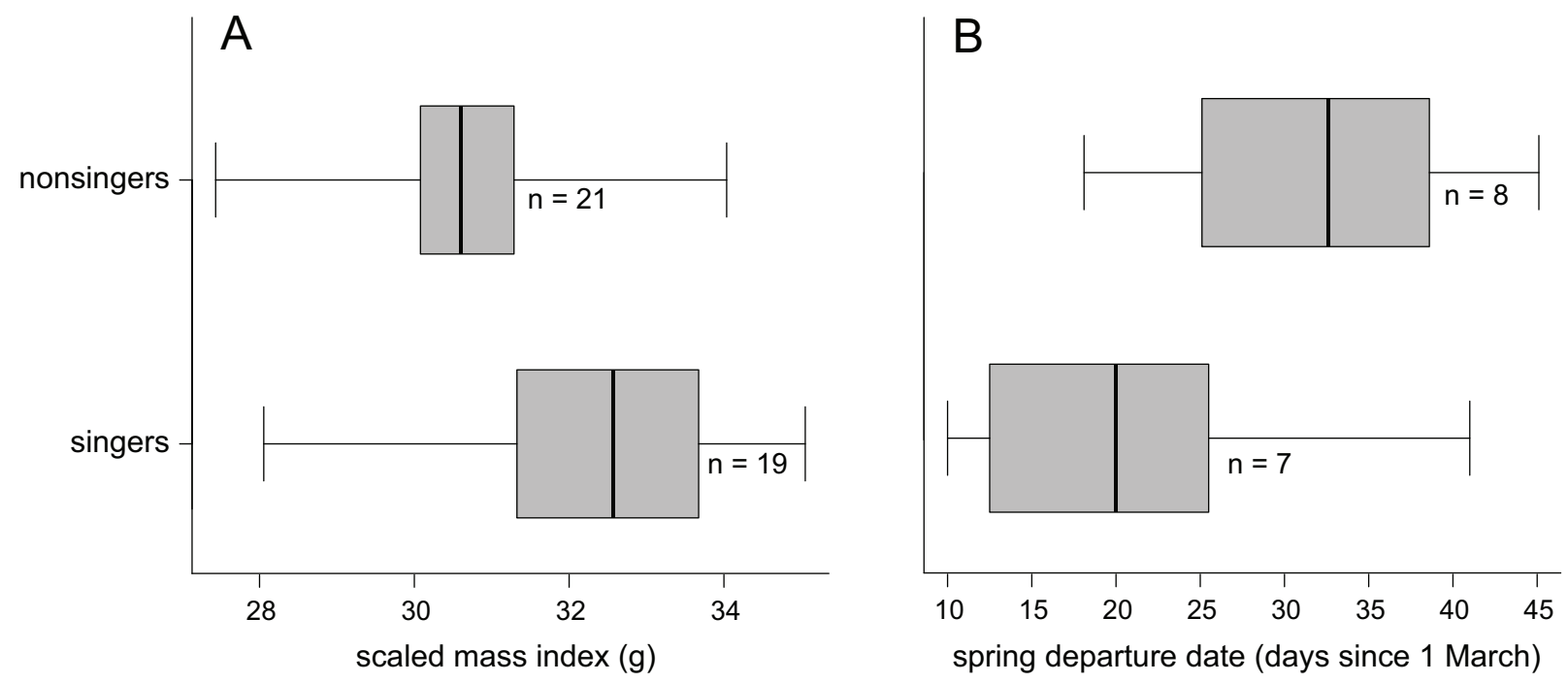

Figure 4: Relationship between the incidence of winter song and two indexes of individual quality in male great reed warblers in Zambia: scaled mass index $\left(t_{36.5}=-3.43, P=.001 ; A\right)$ and departure dates for spring migration $\left(t_{12.4}=2.05, P=.06 ; B\right)$. As predicted by all three hypotheses tested here, males that sing in winter appear to be higher-quality individuals than those that do not sing.

migration approached (fig. 1), and testosterone levels did not increase over time $\left(r^{2}=0.02, f=0.48, P=.49\right)$.

\section{Discussion}

Many Palearctic-African migratory songbird species sing extensively on their nonbreeding grounds south of the Sahara, outside the context of mate attraction and breedingterritory defense; in this article, we asked why they do so.
We studied great reed warblers, a species in which the metabolic and opportunity costs of song are known to be high (Hasselquist and Bensch 2008), as they are in many other species (e.g., Thomas 1999; Berg et al. 2005), implying an adaptive function for this behavior on the nonbreeding grounds. We found no support for two of three hypotheses tested (predictions and results summarized in fig. 3): we found no evidence for the long-assumed territory-defense hypothesis, since great reed warblers were not territorial even

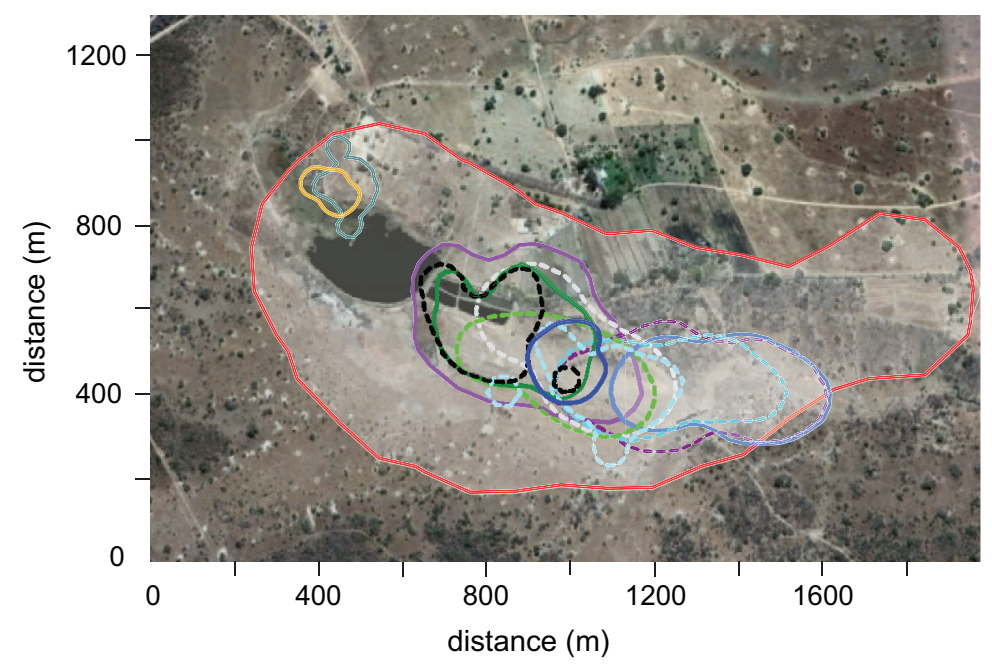

Figure 5: Space-use patterns (95\% kernel density estimates) for wintering male great reed warblers in a subset of the study area (dam $1: 16^{\circ}$ $39^{\prime} 03^{\prime \prime} \mathrm{S}, 27^{\circ} 00^{\prime} 00^{\prime \prime} \mathrm{E}$ ), demonstrating that home ranges overlapped widely, contrary to expectations for the territory-defense hypothesis. Singing males are represented with solid lines, and nonsinging males are represented with dashed lines. 


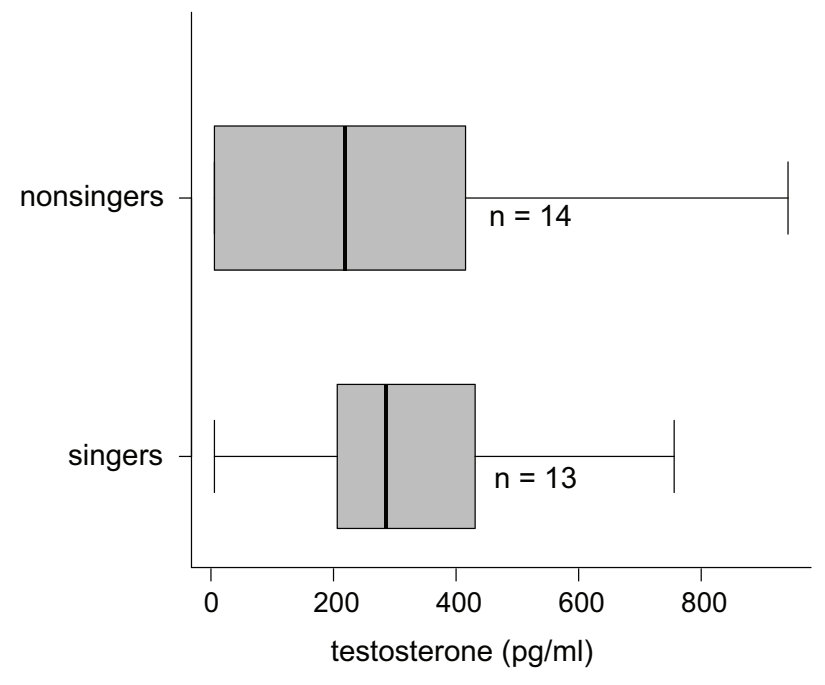

Figure 6: Plasma testosterone concentrations (mean $\pm \mathrm{SE}$ ) for singing and nonsinging great reed warblers, showing that the incidence of winter song is unrelated to circulating testosterone levels $\left(t_{24.9}=-0.83\right.$, $P=.42)$ contrary to expectations for the testosterone hypothesis.

though they invested heavily in winter song (fig. 5); we also found no support for the nonadaptive-testosterone hypothesis, since singing males did not have higher testosterone levels than nonsingers (fig. 6) and singing did not increase as spring migration departure approached (fig. 1; Deviche 1995). Instead, our results are consistent only with the songimprovement hypothesis, which proposes that males invest in winter song to improve song quality and subsequent reproductive success. First, we found that the type of song given by great reed warblers wintering in Africa corresponds to the long song type used for mate attraction on the breeding grounds (fig. 2) rather than the short song type used for territory defense on the breeding grounds. Second, our comparative analysis of 57 Palearctic-African migratory songbird species showed that species that sing more in Africa are those in which males produce more complex songs on the breeding grounds and those with less sexually dichromatic plumage (table 1). These patterns suggest that regular winter singing is associated with strong sexual selection for song, which is consistent with the hypothesis that it functions in song improvement.

The song-improvement hypothesis assumes that, in addition to listening, singing is required to improve song quality. This is supported by the large body of research on song learning in the oscine suborder of passerine birds, in which most song learning takes place in nestlings and young fledglings. Nestlings form a template of sounds from the songs they hear produced by their parents and surrounding conspecifics, which they then recall later as adults (Catchpole and Slater 2003). While listening is essential for song learn- ing, a second required component of song learning is that young birds sing themselves; in the absence of auditory feedback required for vocal refinement, abnormal songs develop (Konishi 1965). Even in adult birds, songs are not hardwired, and the act of singing for oneself has a continued influence, since experimentally deafened adult zebra finches experienced a progressive deterioration of song (Nordeen and Nordeen 1992). Correspondingly, song improvement with age has been demonstrated in a number of PalearcticAfrican migratory songbirds (Gil et al. 2001; Forstmeier et al. 2006; Nicholson et al. 2007), and we suggest that singing in Africa may be important for this annual improvement in song.

For great reed warblers, the potential benefits of improved song quality via winter singing may be particularly high. Song complexity on the breeding grounds strongly predicts several indexes of reproductive success, including the number of females attracted as mates (since great reed warblers can be socially polygynous), the number of extrapair fertilizations, the number of offspring produced, and offspring survival and recruitment (Catchpole 1986; Hasselquist et al. 1996; Hasselquist 1998). Active female choice has also been observed directly, with radio-tracked females visiting an average of six males for 2 or 3 days before pairing (Bensch and Hasselquist 1992). On the wintering grounds in Zambia, we found that only half of wintering males sang and that those that sang left earliest for spring migration and had the highest scaled mass indexes. This suggests that only males with sufficient energy reserves may be able to invest in winter song for the purposes of song learning (Hasselquist and Bensch 2008), whereas lower-quality males may need to forgo singing in order to conserve energy for winter maintenance and spring migration. Great reed warbler males with sufficient energy reserves available to improve song quality over the course of the winter may be at a considerable advantage during subsequent breeding seasons (Forstmeier et al. 2006). However, a direct test would require following individuals between Africa and Europe, which is a considerable practical challenge using currently available tracking technology.

Comparisons between great reed warbler songs produced during breeding and those produced while wintering in Africa give additional support to the song-improvement hypothesis: during breeding, two distinct song types are sung in the contexts of mate attraction, and territory defense and mate guarding, respectively (Catchpole 1983), and we found that great reed warblers sing the former song type in Africa. This adds to the evidence rejecting the territory-defense hypothesis, which would instead predict that wintering birds should sing the shorter (and likely energetically cheaper) song type used specifically in this context. We also found that winter and breeding songs were equally complex, which is also inconsistent with predictions for territorial song, since 
simple, stereotyped, and short songs should better facilitate individual recognition by neighboring territory holders (Catchpole 1980). Finally, we found that winter songs were structurally different from breeding songs: winter songs were longer and switched more often between different syllable types, whereas breeding songs repeated each individual syllable more times. Such syllable redundancy may enhance recognition or perception of information by a receiver (Wiley 1983), such as a female engaged in mate selection. The lower frequency of redundant syllables in winter songs is unsurprising for songs produced in the absence of a receiver. Rather than repeating syllables to ensure perception, we might speculate that birds switch syllables more often to aid practice and song improvement.

Nearctic-Neotropical migrants, although phylogenetically distinct, present an interesting system for comparison. New World passerines use simple chip calls to defend winter territories rather than song (Poole 2005; Morton and Stutchbury 2012). This suggests that calls, which are likely cheaper, less conspicuous to predators, and take less time away from foraging than full song (Catchpole and Slater 2003), are sufficient for territory defense. This lends further support to the suggestion that regular winter song in Palearctic-African migrants may serve a different function even if sung by territorial species (Schwabl 1992). Interestingly, Nearctic-Neotropical migratory warbler species are highly dichromatic (Poole 2005); perhaps the availability of visual cues for male quality might reduce the importance of song for mate attraction and help to explain the general absence of winter singing in the Neotropics.

Our comparative analysis of 57 songbird species in the Palearctic-African migratory system showed, first, that species that invest most heavily in winter singing are those species where males produce the most complex songs during breeding (i.e., have the greatest song repertoire sizes and, after Bonferroni correction, tend to have greater syllable repertoire sizes and versatility indexes). Therefore, since these species are likely to experience more intense sexual selection for song quality on the breeding grounds, they would benefit most from costly song production in Africa. Second, our analysis showed that species that sang most in Africa were least sexually dichromatic, which is consistent with a trade-off between sexually selected investment in song and plumage characteristics if winter song functions for song improvement; dichromatic species should have the least to gain from costly investment in winter song. However, we also note the absence of any relationships between sexual dichromatism and song-complexity measures in our data, which we had expected to arise from such a trade-off, given that it is theoretically impossible to maximally allocate resources to all sexual displays (Roff 1992; Badyaev et al. 2002; but see Shutler and Weatherhead 1990; Mason et al. 2014). This could suggest that visual and vocal signals evolved independently in Palearctic-African migratory songbirds or that song characteristics other than those measured in this study (e.g., syllable sequence, production of unique syllables, frequency range, or song amplitude) may also be important sexually selected components of song.

Finally, we found no support for the nonadaptive elevated testosterone hypothesis. Great reed warbler testosterone levels were at basal levels throughout the winter, suggesting that testosterone carryover from breeding did not occur. In addition, when spring migration approached and testosterone levels might be expected to increase (Deviche 1995), singing intensity instead declined. These results may be unsurprising given that earlier studies of resident and short-distance migrant species also found basal testosterone levels in winter (Logan and Wingfield 1990; Schwabl 1992). Moreover, evidence from other species suggests that different hormonal mechanisms are responsible for nonbreeding song, possibly to circumvent the costs of maintaining elevated testosterone levels in the long term (Ketterson et al. 1991): in winter, dehydroepiandrosterone from the adrenals or regressed testes can be metabolized within the brain to supply specific neural circuits that support song in some species (Soma 2006), suggesting that a secondary control mechanism may have evolved for winter singing in the absence of circulating testosterone. In summary, our results provide strong evidence against the hypothesis that winter song is a nonadaptive consequence of elevated testosterone levels in some individuals, either residual from breeding or rising in anticipation of spring migration.

Taken together, our results provide strongest support for the hypothesis that long-distance migrants sing in winter to improve the quality of their songs rather than to defend nonbreeding territories or as a nonadaptive side effect of circulating testosterone. Exceptions to this function clearly exist (e.g., short-distance migratory robins wintering within Europe almost certainly sing to defend territories; Schwabl 1992), but for species where sexual selection acts strongly on song characteristics, such as Acrocephalus warblers, winter singing may have important consequences for long-term fitness. Further empirical data are needed to assess the importance of winter singing for lifetime reproductive success, in particular, for juveniles producing song in Africa for the first time. This study also underlines how sexual selection can have far-reaching effects on avian ecology throughout the annual cycle.

\section{Acknowledgments}

We thank J. Boyce, J. Jönsson, C. Moya, and K. Mudenda for field and laboratory assistance; S. Bensch for generous access to lab space; D. Hasselquist and W. Sutherland for 
helpful discussion; D. Lukas for statistical guidance; E. and I. Bruce-Miller for their generous hospitality and warmth in Zambia; H. Ross for access to part of the study area; and the Zambian Wildlife Authority for permits. We are also very grateful to F. Dowsett-Lemaire and T. Fulford for sharing their field observations and providing helpful accounts on migrant winter singing behavior and to contributors to the Xeno-Canto website for generously sharing their recordings. M.C.S. was funded by the Gates Cambridge Trust and the Natural Sciences and Engineering Research Council of Canada. C.N.S. was supported by a Royal Society Dorothy Hodgkin Fellowship, a Biotechnology and Biological Sciences Research Council David Phillips Fellowship, and the Department of Science and Technology-National Research Foundation Centre of Excellence at the Percy FitzPatrick Institute. Author contributions: M.C.S. and C.N.S. designed the study, M.C.S. conducted fieldwork, S.J.-E. and M.C.S. conducted lab assays, and M.C.S. wrote the manuscript with contributions from C.N.S. and S.J.-E.

\section{Literature Cited}

Andersson, M. B. 1994. Sexual selection. Princeton University Press, Princeton, NJ.

Badyaev, A. V., G. E. Hill, and B. V. Weckwort. 2002. Species divergence in sexually selected traits: increase in song elaboration is related to decrease in plumage ornamentation in finches. Evolution 56:412-419.

Bensch, S., and D. Hasselquist. 1992. Evidence for active female choice in a polygynous warbler. Animal Behaviour 44:301-311.

Berg, M. L., N. H. Beintema, J. A. Welbergen, and J. Komdeur. 2005. Singing as a handicap: the effects of food availability and weather on song output in the Australian reed warbler Acrocephalus australis. Journal of Avian Biology 36:102-109.

Brosset, A. 1971. Territorialisme et défense du territoire chez les migrateurs Paléarctiques hivernant au Gabon. Alauda 39:127-131.

Calenge, C. 2006. The package "adehabitat" for the R software: a tool for the analysis of space and habitat use by animals. Ecological Modelling 197:516-519.

Cannam, C., C. Landone, and M. Sandler. 2010. Sonic visualiser: an open source application for viewing, analysing, and annotating music audio files. Proceedings of the ACM Multimedia 2010 International Conference, New York.

Catchpole, C. 1983. Variation in the song of the great reed warbler Acrocephalus arundinaceus in relation to mate attraction and territorial defence. Animal Behaviour 31:1217-1225.

Catchpole, C., B. Leisler, and J. Dittami. 1986. Sexual differences in the responses of captive great reed warblers Acrocephalus arundinaceus to variation in song structure and repertoire size. Ethology 73:6977.

Catchpole, C. K. 1980. Sexual selection and the evolution of complex songs among European warblers of the genus Acrocephalus. Behaviour 74:149-165.

1986. Song repertoires and reproductive success in the great reed warbler Acrocephalus arundinaceus. Behavioral Ecology and Sociobiology 19:439-445.
Catchpole, C. K., and P. Slater. 2003. Bird song: biological themes and variations. Cambridge University Press, New York.

Cramp, S., and C. M. Perrins. 1994. The birds of the Western Palearctic. Oxford University Press, Oxford.

Deviche, P. 1995. Androgen regulation of avian premigratory hyperphagia and fattening: from eco-physiology to neuroendocrinology. American Zoologist 35:234-245.

Dowsett, R. J., D. R. Aspinwall, and F. Dowsett-Lemaire. 2008. The birds of Zambia: an atlas and handbook. Tauraco \& Aves, Liège, Belgium.

Dowsett-Lemaire, F. 1979. The imitative range of the song of the marsh warbler Acrocephalus palustris, with special reference to imitations of African birds. Ibis 121:453-468.

Forstmeier, W., D. Hasselquist, S. Bensch, and B. Leisler. 2006. Does song reflect age and viability? a comparison between two populations of the great reed warbler Acrocephalus arundinaceus. Behavioral Ecology and Sociobiology 59:634-643.

Fridolfsson, A.-K., and H. Ellegren. 1999. A simple and universal method for molecular sexing of non-ratite birds. Journal of Avian Biology 30:116.

Fusani, L. 2008. Testosterone control of male courtship in birds Hormones and Behavior 54:227-233.

Gil, D., J. L. Cobb, and P. J. Slater. 2001. Song characteristics are age dependent in the willow warbler, Phylloscopus trochilus. Animal Behaviour 62:689-694.

Gil, D., and M. Gahr. 2002. The honesty of bird song: multiple constraints for multiple traits. Trends in Ecology and Evolution 17: 133-141.

Grafen, A. 1989. The phylogenetic regression. Proceedings of the Royal Society B: Biological Sciences 326:119-157.

Hansen, T. F. 1997. Phylogenies and the comparative method: a general approach to incorporating phylogenetic information into the analysis of interspecific data. American Naturalist 149:646667.

Hasselquist, D. 1998. Polygyny in great reed warblers: a long-term study of factors contributing to male fitness. Ecology 79:23762390.

Hasselquist, D., and S. Bensch. 2008. Daily energy expenditure of singing great reed warblers Acrocephalus arundinaceus. Journal of Avian Biology 39:384-388.

Hasselquist, D., S. Bensch, and T. von Schantz. 1996. Correlation between male song repertoire, extra-pair paternity and offspring survival in the great reed warbler. Nature 381:229-232.

Hedenström, A., S. Bensch, D. Hasselquist, M. Lockwood, and U. Ottosson. 1993. Migration, stopover and moult of the great reed warbler Acrocephalus arundinaceus in Ghana, west Africa. Ibis 135:177-180.

Kelsey, M. G. 1988. A comparison of the song and territorial behaviour of a long-distance migrant, the marsh warbler Acrocephalus palustris, in summer and winter. Ibis 131:403-414.

Ketterson, E. D., V. Nolan, L. Wolf, C. Ziegenfus, A. M. Dufty, G. F. Ball, and T. S. Johnsen. 1991. Testosterone and avian life histories: the effect of experimentally elevated testosterone on corticosterone and body mass in dark-eyed juncos. Hormones and Behavior 25:489-503.

Kipper, S., and S. Kiefer. 2010. Age-related changes in birds' singing styles: on fresh tunes and fading voices? Advances in the Study of Behavior 41:77-118.

Konishi, M. 1965. The role of auditory feedback in the control of vocalization in the white-crowned sparrow. Zeitschrift für Tierpsychologie 22:770-783. 
Lemke, H. W., M. Tarka, R. Klaassen, M. Åkesson, S. Bensch, D. Hasselquist, and B. Hansson. 2013. Annual cycle and migration strategies of a trans-Saharan migratory songbird: a geolocator study in the great reed warbler. PLoS ONE 8:e79209.

Logan, C. A., and J. C. Wingfield. 1990. Autumnal territorial aggression is independent of plasma testosterone in mockingbirds. Hormones and Behavior 24:568-581.

Marra, P. P. 2000. The role of behavioral dominance in structuring patterns of habitat occupancy in a migrant bird during the nonbreeding season. Behavioral Ecology 11:299-308.

Mason, N. A., A. J. Shultz, and K. J. Burns. 2014. Elaborate visual and acoustic signals evolve independently in a large, phenotypically diverse radiation of songbirds. Proceedings of the Royal Society B Biological Sciences 281:20140967.

Morton, E. S., and B. J. M. Stutchbury. 2012. Vocal communication in androgynous territorial defense by migratory birds. ISRN Zool ogy 2012:1-9.

Nicholson, J., K. Buchanan, and R. Marshall. 2007. Song sharing and repertoire size in the sedge warbler, Acrocephalus schoenobaenus: changes within and between years. Animal Behaviour 74:1585-1592.

Nordeen, K. W., and E. J. Nordeen. 1992. Auditory feedback is necessary for the maintenance of stereotyped song in adult zebra finches. Behavioral and Neural Biology 57:58-66.

Oberweger, K., and F. Goller. 2001. The metabolic cost of birdsong production. Journal of Experimental Biology 204:3379-3388.

Owens, I. P. F., and P. M. Bennett. 1994. Mortality costs of parental care and sexual dimorphism in birds. Proceedings of the Royal Society B: Biological Sciences 257:1-8.

Peig, J., and A. J. Green. 2009. New perspectives for estimating body condition from mass/length data: the scaled mass index as an alternative method. Oikos 118:1883-1891.

Poole, A. 2005. The Birds of North America Online. Cornell Lab of Ornithology, Ithaca, NY. http://bna.birds.cornell.edu/bna.

Rappole, J. H., and A. R. Tipton. 1991. New harness design for attachment of radio transmitters to small passerines. Journal of Field Ornithology 62:335-337.

R Development Core Team. 2012. R: a language and environment for statistical computing. R Foundation for Statistical Computing, Vienna.

Read, A. F., and D. M. Weary. 1992. The evolution of bird song: comparative analyses. Philosophical Transactions of the Royal Society B: Biological Sciences 338:165-187.

Roff, D. A. 1992. Evolution of life histories: theory and analysis. Chapman \& Hall, New York.
Round, P. D., B. Hansson, D. J. Pearson, P. R. Kennerley, and S. Bensch. 2007. Lost and found: the enigmatic large-billed reed warbler Acrocephalus orinus rediscovered after 139 years. Journal of Avian Biology 38:133-138.

Ruxton, G. D. 2006. The unequal variance $t$-test is an underused alternative to Student's $t$-test and the Mann-Whitney $U$ test. Behavioral Ecology 17:688-690.

Schwabl, H. 1992. Winter and breeding territorial behaviour and levels of reproductive hormones of migratory European robins. Ornis Scandinavica 23:271-276.

Seaman, D. E., and R. A. Powell. 1996. An evaluation of the accuracy of kernel density estimators for home range analysis. Ecology 77: 2075-2085.

Seddon, N., J. A. Tobias, M. Eaton, A. Ödeen, and B. E. Byers. 2010. Human vision can provide a valid proxy for avian perception of sexual dichromatism. Auk 127:283-292.

Shutler, D., and P. J. Weatherhead. 1990. Targets of sexual selection: song and plumage of wood warblers. Evolution 44:1967-1977.

Soma, K. K. 2006. Testosterone and aggression: Berthold, birds and beyond. Journal of Neuroendocrinology 18:543-551.

Sorensen, M. C. 2014. Singing in Africa: no evidence for a long supposed function of winter song in a migratory songbird. Behavioral Ecology 25:909-915.

Sorensen, M. C., S. Jenni-Eiermann, and C. N. Spottiswoode. 2015 Data from: Why do migratory birds sing on their tropical wintering grounds? American Naturalist, Dryad Digital Repository, http://dx.doi.org/10.5061/dryad.38f3n.

Svensson, L., P. J. Grant, K. Mullarney, and D. Zetterström. 2009. Collins bird guide. Harper Collins, London.

Thomas, R. 1999. Two tests of a stochastic dynamic programming model of daily singing routines in birds. Animal Behaviour 57: 277-284.

Verheyen, R. K. 1953. Exploration du Parc National de l'Upemba, fascicule 19. Institut des Parcs Nationaux du Congo Belge, Bruxelles.

Ward, S., J. R. Speakman, and P. J. Slater. 2003. The energy cost of song in the canary, Serinus canaria. Animal Behaviour 66:893902.

Wiley, R. H. 1983. The evolution of communication: information and manipulation. Pages 156-189 in T. R. Halliday and P. J. B. Slater, eds. Animal behaviour. W. H. Freeman, New York.

Associate Editor: Tony D. Williams Editor: Judith L. Bronstein 